\title{
The potential impact of COVID-19 infection on tuberculosis: a literature review
}

\author{
Muhammad Mahmood Akhtar ${ }^{1 *}$, Saud Talaq Alotaibi ${ }^{2}$, Abdullah Fayez Althubeti ${ }^{2}$, \\ Shaker Awwad Alharthi ${ }^{2}$, Shikih Hussain Alhassan ${ }^{3}$, Malath Abdulrahman Bukhari, \\ Abdulrahman Faris Alamri², Abdulaziz Faris Alamri², Abdulaziz Khalafallah Alnumari \\ Nasser Eid Alsufyani², Abdullah Hassan Alhamoud ${ }^{5}$
}

\author{
${ }^{1}$ Department of Internal Medicine, East Jeddah Hospital, Jeddah, Saudi Arabia \\ ${ }^{2}$ College of Medicine, Taif University, Taif, Saudi Arabia \\ ${ }^{3}$ Department of Internal Medicine, Ministry of Health, Qatif, Saudi Arabia \\ ${ }^{4}$ College of Medicine, Ibn Sina National College, Jeddah, Saudi Arabia \\ ${ }^{5}$ College of Medicine, King Saud bin Abdulaziz University for Health Sciences, Riyadh, Saudi Arabia
}

Received: 20 December 2020

Revised: 06 January 2021

Accepted: 07 January 2021

\section{*Correspondence:}

Dr. Muhammad Mahmood Akhtar,

E-mail: docmahmood@gmail.com

Copyright: ( ) the author(s), publisher and licensee Medip Academy. This is an open-access article distributed under the terms of the Creative Commons Attribution Non-Commercial License, which permits unrestricted non-commercial use, distribution, and reproduction in any medium, provided the original work is properly cited.

\begin{abstract}
Tuberculosis is among the oldest endemic conditions affecting humans; however, it remains a significant health issue around the globe. As with previous outbreaks/epidemics, the COVID-19 impact on TB control efforts and outcomes should raise concerns; however, the extent of this impact is currently unknown. In the current study, we aim to review the literature to provide an overview of the available evidence discussing the impact of coronavirus disease-2019 (COVID-19) on TB infections. On one hand, many of the existing reports showed that having TB infection may contribute to developing severe forms of acute respiratory syndrome in patients co-infected with COVID-19, and the presence of underlying TB infection was identified as a risk factor for COVID-19 infection. However, other reports showed that patients with present TB were not more vulnerable to get infected with COVID-19 or to higher mortality rates. In the same context, COVID-19 may have an impact on the late reactivation of TB, which could be mediated through its effects on the immune system functionality and subsequent development of active TB. Moreover, TB preventive treatment programs, awareness campaigns, and anti-TB funding were also affected by COVID-19. Accordingly, the global strategy to end the TB by 2035 may be affected by the COVID-19 pandemic. Hospital admission for TB patients should be restricted to severe cases, to prevent the transmission of COVID-19 in those cases. Due to scarce evidence, more studies are needed to guide management plans in this particular context.
\end{abstract}

Keywords: COVID-19, Tuberculosis, Co-infection, Burden

\section{INTRODUCTION}

Tuberculosis (TB) is among the oldest endemic conditions affecting humans; however, it remains a significant health issue around the globe. ${ }^{1,2}$ The latent TB infection is estimated to be affecting one-quarter of the world's population (TB dormant form). ${ }^{3}$ It is estimated, by the world health organization (WHO), that ten million individuals develop active TB and more than one million ones pass away due to TB, every year. ${ }^{4}$ The burden of TB has declined rapidly following the development of TB medications and improvement in the population's socioeconomic status, with subsequent control in high- 
income countries. ${ }^{5,6}$ Nevertheless, TB re-emerged in the 1980 s, with the appearance of the human immunodeficiency virus (HIV) pandemic; leading to high mortality in millions worldwide. ${ }^{7}$ Accordingly, the morbidity and mortality of TB started to decrease, over the past decades, as a result of using antiretroviral therapy (ART) in managing HIV. ${ }^{8}$

Recently, different viral outbreaks emerged in several spots of the world; posing new difficulties for efforts of TB control, whether on the national or global scales. For instance, the TB programs in West African countries were majorly damaged following the Ebola outbreak. ${ }^{9,10}$ Similarly, TB control efforts in Saudi Arabia have compromised following the Middle East respiratory syndrome coronavirus (MERS-CoV) outbreaks. ${ }^{11}$ Accordingly, there was an increase in the TB burden among the countries affected by viral outbreaks over the following years. Ending the TB epidemic, by 2030, is among the United Nations sustainable development goals (SDGs) and the WHO ambitious targeting a 90\% TB reduction (compared to 2015 rates), by 2035. ${ }^{12,13}$ Before the COVID-19 pandemic, the deaths from TB were over 4000 individuals daily. ${ }^{4}$ As with previous outbreaks/epidemics, the COVID-19 impact on TB control efforts and outcomes should raise concerns; however, the extent of this impact is currently unknown. ${ }^{14,15}$ Driven by the high load of COVID-19 cases and measures to control its transmission, there is an obvious reduction in the availability of health services needed for the diagnosis and management of TB cases. ${ }^{16}$ Although COVID-19 related social distancing may limit Mycobacterium tuberculosis (MTB) non-household transmission, it is not clear if this can compensate for the shortage in TB health services. ${ }^{17}$ In the current study, we aim to review the literature to provide an overview of the available evidence discussing the impact of COVID-19 on TB infections.

An extensive literature search of the Medline, Cochrane, and EMBASE databases was performed on 20 November 2020 using the medical subject headings (MeSH) or a combination of all possible related terms. Papers discussing the impact of COVID-19 on TB infections were screened for relevant information. We did not pose any limits on date, language, age of participants, or publication type.

\section{LESSONS FROM PAST EPIDEMICS/PANDEMICS}

To improve understanding of the management of the novel coronavirus pandemic, understanding the experience is needed. Since the emergence of the coronaviruses in 1960, three human types were identified with their ability to cause fatal respiratory conditions. In 2002, a global epidemic was caused by the severe acute respiratory syndrome (SARS) coronavirus, followed by the Middle-East respiratory syndrome coronavirus (MERS-CoV) in 2012, which has been identified in 27 countries so far. ${ }^{18,19}$ Recently, COVID-19 has emerged; causing an ongoing pandemic with growing daily numbers of new cases and deaths around worldwide. ${ }^{20}$ COVID-19 has high transmissibility similar to that of the 1918-1919 pandemic; the on-third of the world population was estimated to be affected, with a $2.5 \%$ mortality rate. ${ }^{21}$ Moreover, the COVID-19-induced acute respiratory distress syndrome (ARDS) showed pathological similarities with H7N9-associated ARDS. ${ }^{22}$ However, the influenza pandemics showed lower fatality among healthcare workers, compared to SARS, MERS, and COVID-19 infections. ${ }^{23}$

Among TB patients, it has been shown that inducing type I interferons (IFNs), as mediated by influenza infection, can affect the ability of competent individuals to control MTB replication. ${ }^{24}$ Accordingly, promoting the infection and increasing TB mortality; it was noted that the mortality rate caused by pneumonia and influenza amidst the age group most affected by TB was higher during the 1918 pandemic, compared to death rates before and following it. ${ }^{25,26}$ During winter months, in coincidence with seasonal influenza, TB-related deaths were higher, which may suggest that pulmonary TB is a risk factor for mortality among influenza patients. ${ }^{27}$ In contrast, some studies reported the absence of a significant association between the pulmonary TB severity and influenza coinfection. ${ }^{28,29}$ Also, an animal study showed that the influenza-induced IFN- $\gamma$ increase had little effect on the bacterial load in BCG-infected murine model ${ }^{29}$. Furthermore, a recent systematic review did not show a significant impact of influenza on pulmonary TB clinical picture or outcomes, and vice versa. ${ }^{30}$

In china TB patients infected with SARS form the exposure to patients admitted within the same hospital wards, which could have been prevented. ${ }^{31}$ Although, most of those patients recovered with no serious complication, the SARS-TB co-infection was accompanied by a significant reduction in average CD4+, $\mathrm{CD} 8+$, and low antibody levels following recovery from SARS. ${ }^{31}$ A possible higher spread of SARS may be associated with the presence of TB since the viral excretion was for longer durations I stool of TB-SARS co-infected patients, compared to those with SARS infection alone. ${ }^{31}$ In Taiwan, during a screening related to SARS infection, 60 healthcare workers were found to have TB. ${ }^{32}$ Moreover, during the SARS epidemic, SARS cases developed active pulmonary TB following the recovery from SARS, which is consistent with previous animal models showing a cellular immunity attenuation following viral infection. ${ }^{24,31}$ Similarly, the MERS-CoV infection was found to augment the TB infection through the immunosuppression, and accordingly, discovering the coexisting TB should be always done in SARS and MERS-CoV patients. ${ }^{11}$

\section{PATHOLOGICAL ASSOCIATION BETWEEN TB AND COVID-19}

The pathophysiology of COVID-19 is not fully digested; however, it seems to be similar to the one of SARS infection. The COVID-19 infection can induce severe inflammation by enhancing cytokine release; resulting in 
the so-called "cytokine storm", which may explain the severe disease in young patients. ${ }^{33}$ Noteworthy, cytokines have an important role in the resistance of the host to the TB infection, which was confirmed by the findings of severe MTB disease in individuals with IFN- $\gamma$ and IL-12 signaling pathway mutations or those with Crohn's disease or rheumatoid arthritis and receiving $\mathrm{TNF}-\alpha$ blockers. ${ }^{25,34}$ Established and possible interactions between MTB and coronaviruses is shown if (Figure 1). ${ }^{35}$

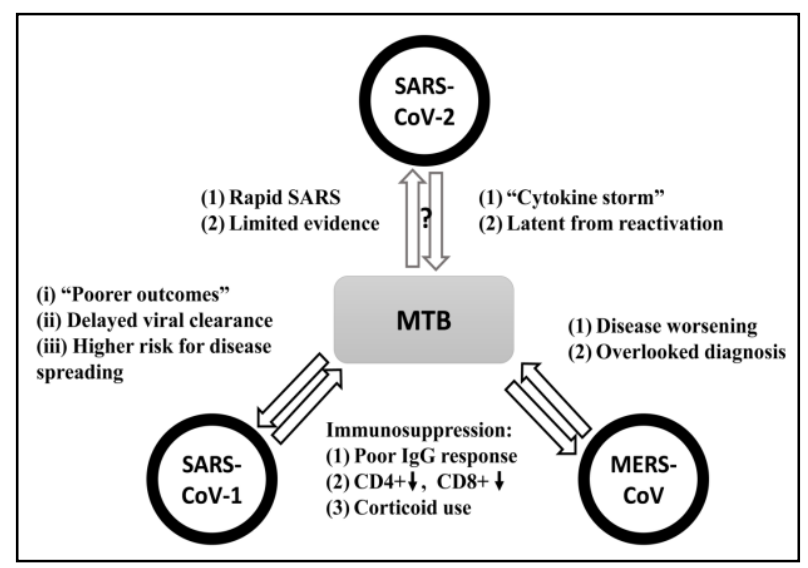

Figure 1: Established and possible interactions between MTB and coronaviruses.

\section{IMPACT OF COVID-19 ON TB PATIENTS}

There is limited evidence on the COVID-19-TB coinfection, nevertheless, existing reports showed that having TB infection may contribute to developing severe forms of acute respiratory syndrome in patients coinfected with COVID-19. ${ }^{33,36,37}$ According to a recent meta-analysis, the presence of underlying TB infection was identified as a risk factor for COVID-19 infection, increasing its severity and mortality rates, and decreasing disease recovery. ${ }^{38}$ In contrast, another meta-analysis showed that patients with present TB were not more vulnerable to get infected with COVID-19 or to higher mortality rates; however, the same study acknowledged that there was a 2.1-fold increase in the risk of developing severe forms of COVID-19 disease, with no statistical significance. ${ }^{39}$ It should be mentioned that the latter study included a small number of TB patients with COVID-19 co-infection and the risk of bias was not assessed in a rigorous way. ${ }^{39}$ In the same context, a cohort study of 69 COVID-19-TB co-infection, the COVID-19 worsened the prognosis of TB patients; nevertheless, TB was not a significant predictor of mortality. ${ }^{40}$ In case series of 20 patients with COVID-19-TB co-infection, except for one patient who died, there was no major impact of COVID19 on active TB infection, with no obvious clinical deterioration, no intensive care unit admissions, no newonset pneumonia and no worsening of TB lesions in chest $\mathrm{X}$-ray. ${ }^{41}$ However, this study was limited by small number of patients, the young age of most of the included individuals, and low frequency of significant co- morbidities and multidrug-resistant $\mathrm{TB} .{ }^{41}$ In the same context, COVID-19 may have an impact on the late reactivation of $\mathrm{TB}$, which could be mediated through its effects on the immune system functionality and subsequent development of active TB. ${ }^{42,43}$ COVI-19related pneumonia and respiratory failure may inflict long-standing respiratory system damage, which would result in enhancing TB risk. ${ }^{44}$ Furthermore, the evidence shows that viral infections (as HIV and influenza) can take a part in developing active TB, either directly the following exposure to $\mathrm{TB}$ or indirectly by re-activating a latent TB infection. ${ }^{45-47}$

\section{IMPACT OF COVID-19 ON TB CONTROL AND BURDEN}

A mentioned before, the strategies for TB prevention and control are always compromised at times of outbreaks, which applies to the current COVID-19 pandemic. For instance, on March 24 every year, the world tuberculosis day is celebrated to enhance disease-related awareness and to raise funding; it was canceled in many countries due to the COVID-19 situation. ${ }^{15}$ Moreover, the BCG vaccination programs, administered to prevent TB in children, were negatively influenced by COVID-19 infection. ${ }^{48}$ Moreover, programs of preventive treatment targeting the high-risk groups, to prevent the progression of latent $\mathrm{TB}$ to the active one, were also affected by COVID-19. ${ }^{49}$ Accordingly, the global strategy to end the TB by 2035 may be affected by the COVID-19 pandemic. McQuaidc et al constructed mathematical modeling to measure the combined effect of COVID-19 related shortage in TB control measures and the possible benefit of COVID-19-associated social distancing on TB burden. ${ }^{50}$ Their results showed an $8-14 \%$ increase in the cumulative TB mortality between 2020-2024, with a total of 201,595 deaths in China, India, and South Africa alone. ${ }^{50}$ They concluded that this damaging spike in mortality can be minimized by the impact of COVID-19 on the delivery of TB health services along with a strict reduction in social contacting. ${ }^{50}$ They also anticipated that external factors like poverty rates increase and decline in the access to antiretroviral therapy within a country with high HIV prevalence; could increase the incidence of TB infection. ${ }^{50}$ Noteworthy, the effect of social distancing was more favorable on TB incidence rather than TB death rates. ${ }^{50}$ The COVID-19 pandemic would cause severe economic damage in national and global aspects. This crisis will have a negative impact on the less fortunate people with fewer jobs, reduced remittances, high prices, and changes in the services provided; including education and health care sectors. ${ }^{51}$ AS per the World Bank, driven by the COVID-19 crisis, 2020 will have an increase in the extreme poverty rate (0.3-0.07 percent points) and 40-60 million populations will be in the extreme poverty category, which will have a long-lasting impact on the TB burden. $^{52}$ The reason for that is the poverty being recognized as an impending risk factor for TB infections, whether new or re-activated one. ${ }^{52-54}$ 
Table 1: Strategies to Mitigate the Impact of COVID-19 on TB Control. ${ }^{42}$

\begin{tabular}{|c|c|}
\hline Impact of COVID-19 on TB & Strategies to mitigate the impact of COVID-19 on TB control \\
\hline \multirow{6}{*}{$\begin{array}{l}\text { Increased household } \\
\text { transmission of TB }\end{array}$} & $\begin{array}{l}\text { Apply infection prevention and control measures (e.g., cough etiquette,personal } \\
\text { protective equipment). }\end{array}$ \\
\hline & Consider using upper-room germicidal ultraviolet (GUV)where indicated. \\
\hline & $\begin{array}{l}\text { Apply room ventilation (including natural, mixed-mode, mechanical ventilation, and } \\
\text { recirculated air through high-efficiency particulate air (HEPA) filters). }\end{array}$ \\
\hline & Separate or isolate people with presumed or demonstrated infectious TB. \\
\hline & Provide TB preventive treatment for high-risk groups. \\
\hline & Initiate TB treatment early. \\
\hline \multirow{10}{*}{$\begin{array}{l}\text { Delayed TB diagnosis and } \\
\text { treatment services }\end{array}$} & $\begin{array}{l}\text { Maintain supports to essential TB services during and after the COVID-19 } \\
\text { pandemic. }\end{array}$ \\
\hline & $\begin{array}{l}\text { Provide information to patients about COVID-19 and TB so they can protect } \\
\text { themselves and continue their TB treatment. }\end{array}$ \\
\hline & $\begin{array}{l}\text { Apply patient-centred delivery of TB prevention, diagnosis, treatment, and care } \\
\text { services. }\end{array}$ \\
\hline & $\begin{array}{l}\text { Decentralise TB treatment to community health workers and increase access to TB } \\
\text { treatment for home-based TB care. }\end{array}$ \\
\hline & Provide adequate supply of TB medication to patients for safe storage at home. \\
\hline & $\begin{array}{l}\text { Design mechanisms to deliver medicines and to collect specimens for follow-up } \\
\text { testing at home. }\end{array}$ \\
\hline & $\begin{array}{l}\text { Integrate TB and COVID-19 services for infection control, contact tracing, } \\
\text { community-based care, surveillance and monitoring. }\end{array}$ \\
\hline & $\begin{array}{l}\text { Provide short-term training for students and health professionals and recruit } \\
\text { additional staff to work on TB programs. }\end{array}$ \\
\hline & $\begin{array}{l}\text { Change policy if required and support private hospitals, and academic or research } \\
\text { centres, to provide TB testing and treatment. }\end{array}$ \\
\hline & $\begin{array}{l}\text { Use virtual care and digital health technologies (e.g., video observed therapy) for } \\
\text { adherence support, early initiation of treatment, remote monitoring of TB patients, } \\
\text { counselling, and follow-up consultations. }\end{array}$ \\
\hline \multirow{3}{*}{$\begin{array}{l}\text { Affecting TB prevention and } \\
\text { control strategies }\end{array}$} & Organize virtual conferences, seminars, workshops and fundraising. \\
\hline & Design strategies to deliver BCG and TB preventive therapy at home. \\
\hline & Create community awareness of the importance of TB services. \\
\hline \multirow[b]{2}{*}{ Reactivation of TB } & Plan additional support and resources to reduce the burden of TB. \\
\hline & $\begin{array}{l}\text { Conduct research to identify the impact of COVID-19 on reactivation of TB and to } \\
\text { design interventions mitigating this problem. }\end{array}$ \\
\hline
\end{tabular}

Alene et al proposed some possible strategies to "mitigate the impact of COVID-19 on TB control", which are represented in (Table 1). ${ }^{48}$

\section{CONCLUSION}

COVID-19 and TB attenuate the host's immune responses; this fatal synergism can contribute to higher severity and clinical deterioration. Coinfection with COVID-19 and TB most probably affecting both sides of the patients: causing severe acute respiratory syndrome through cytokine-dependent immune response and enhancing TB reactivation risk. Hospital admission for TB patients should be restricted to severe cases, to prevent the transmission of COVID-19 in those cases. In spite of the increasing number of COVID-19 cases, there are no enough data to accurately measure the impact of the COVID-19 pandemic on patients with TB. More studies are needed to guide management plans in this particular context.

Funding: No funding sources

Conflict of interest: None declared

Ethical approval: Not required

\section{REFERENCES}

1. Comas I, Coscolla M, Luo T. Out-of-Africa migration and Neolithic coexpansion of Mycobacterium tuberculosis with modern humans. Nat Genet. 2013;45(10):1176-82.

2. The global burden of tuberculosis: results from the global burden of disease study 2015. Lancet Infect Dis. 2018;18(3):261-84. 
3. Houben RM, Dodd PJ. The Global Burden of Latent Tuberculosis Infection: A Re-estimation Using Mathematical Modelling. PLoS Med. 2016;13(10): e1002152.

4. World health organization. Global tuberculosis report 2019. Available at: https://www.who.int/teams/ global-tuberculosis-programme/tb-reports/globalreport-2019. Accessed on 20 November 2020.

5. Glaziou P, Floyd K, Raviglione $M$. Trends in tuberculosis in the UK. Thorax. 2018;73(8):702-3.

6. Motala S, Ngandu S, Mti S. Millennium development goals: Country report 2015. Available at: https://www.un.org/millenniumgoals/2015_MDG_Re port/pdf/MDG\%202015\%20rev\%20(July\%201).pdf. Accessed on 20 November 2020.

7. Corbett EL, Watt CJ, Walker N. The growing burden of tuberculosis: global trends and interactions with the HIV epidemic. Arch Int Med. 2003;163(9):100921.

8. Edmonds A, Lusiama J, Napravnik S, Kitetele F, Van Rie A, Behets F. Anti-retroviral therapy reduces incident tuberculosis in HIV-infected children. Int $\mathrm{J}$ Epidemiol. 2009;38:1612-21.

9. Zachariah R, Ortuno N, Hermans V, Desalegn W, Rust S, Reid AJ, Boeree MJ, Harries AD. Ebola, fragile health systems and tuberculosis care: a call for pre-emptive action and operational research. Int $\mathbf{J}$ Tuberc Lung Dis. 2015;19(11):1271-5.

10. Ansumana R, Keitell S, Roberts GM. Impact of infectious disease epidemics on tuberculosis diagnostic, management, and prevention services: experiences and lessons from the 2014-2015 Ebola virus disease outbreak in West Africa. Int J Infect Dis. 2017;56:101-4.

11. Alfaraj SH, Al-Tawfiq JA, Altuwaijri TA, Memish ZA. Middle east respiratory syndrome coronavirus and pulmonary tuberculosis coinfection: implications for infection control. Intervirol. 2017;60(1-2):53-5.

12. Uplekar M, Weil D, Lonnroth K. WHO's new end TB strategy. Lancet. 2015;385(9979):1799-801.

13. Lönnroth K, Raviglione M. The WHO's new End TB Strategy in the post-2015 era of the Sustainable Development Goals. Trans R Soc Trop Med Hyg. 2016;110(3):148-50.

14. Parpia A, Mbah M, Wenzel N, Galvani A. Effects of Response to 2014-2015 Ebola outbreak on deaths from malaria, hiv/aids, and tuberculosis, West Africa. Emerg Infect Dis. 2016;22.

15. Wingfield T, Cuevas LE, MacPherson P, Millington KA, Squire SB. Tackling two pandemics: a plea on world tuberculosis day. Lancet Respir Med. 2020;8 (6):536-8.

16. Pang Y, Liu Y, Du J, Gao J, Li L. Impact of COVID19 on tuberculosis control in China. Int $\mathrm{J}$ Tuberc Lung Dis. 2020;24(5):545-7.

17. Glynn JR, Guerra-Assunção JA, Houben RM. Whole Genome sequencing shows a low proportion of tuberculosis disease is attributable to known close contacts in rural malawi. PloS one. 2015;10(7): e0132840.
18. Organization WH. MERS situation update, January 2020. Available at: http://www emro who int/healthtopics/mers-cov/mersoutbreaks html (2902 2020). Accessed on 20 November 2020.

19. He J-f, Peng G-w, Zheng H-z. An epidemiological study on the index cases of severe acute respiratory syndrome occurred in different cities among Guangdong province. Zhonghua Liu Xing Bing Xue Za Zhi. 2003;24(5):347-9.

20. Li J-Y, You Z, Wang Q, et al. The epidemic of 2019novel-coronavirus (2019-nCoV) pneumonia and insights for emerging infectious diseases in the future. Microbes Infect. 2020;22(2):80-5.

21. Oei $W$, Nishiura $H$. The relationship between tuberculosis and influenza death during the influenza (H1N1) pandemic from 1918-19. Comput Math Methods Med. 2012;2012:124861.

22. Chen J, Hu C, Chen L. Clinical study of mesenchymal stem cell treatment for acute respiratory distress syndrome induced by epidemic influenza a (h7n9) infection: a hint for covid-19 treatment. Engineering (Beijing). 2020;6(10):115361.

23. Rello J, Tejada S, Userovici C, Arvaniti K, Pugin J, Waterer G. Coronavirus disease 2019 (COVID-19): A critical care perspective beyond China. Anaesth Criti Care Pain Med. 2020;39(2):167-9.

24. Redford PS, Mayer-Barber KD, McNab FW. Influenza A virus impairs control of Mycobacterium tuberculosis coinfection through a type I interferon receptor-dependent pathway. J Infect Dis. 2014;209 (2):270-4

25. Mayer-Barber KD, Sher A. Cytokine and lipid mediator networks in tuberculosis. Immun Rev. 2015;264(1):264-75.

26. Oei $W$, Nishiura $H$. The relationship between tuberculosis and influenza death during the influenza (H1N1) pandemic from 1918-19. Comput Math Methods Med. 2012;2012:124861.

27. Walaza S, Cohen C, Nanoo A. Excess mortality associated with influenza among tuberculosis deaths in South Africa, 1999-2009. PloS one. 2015;10(6): e0129173.

28. Roth S, Whitehead S, Thamthitiwat S. Concurrent influenza virus infection and tuberculosis in patients hospitalized with respiratory illness in Thailand. Influenza Other Respir Viruses. 2013;7(3):244-8.

29. Co DO, Hogan LH, Kármán J. Interactions between $\mathrm{T}$ cells responding to concurrent mycobacterial and influenza infections1. J Immunol. 2006;177:8456-65.

30. Walaza S, Cohen C, Tempia S. Influenza and tuberculosis co-infection: A systematic review. Influenza Other Respir Viruses. 2020;14(1):77-91.

31. Liu W, Fontanet A, Zhang P-H. Pulmonary tuberculosis and SARS, China. Emerg Infect Dis. 2006;12(4):707-9.

32. Centers for Disease Control and Prevention (CDC). Nosocomial transmission of Mycobacterium tuberculosis found through screening for severe acute 
respiratory syndrome-Taipei, Taiwan, 2003. MMWR Morb Mortal Wkly Rep. 2004;53(15):321-2.

33. Guan W-j, Ni Z-y, Hu Y. Clinical characteristics of coronavirus disease 2019 in China. N Eng J Med. 2020;382(18):1708-20.

34. Harris J, Keane J. How tumour necrosis factor blockers interfere with tuberculosis immunity. Clin Exper Immunol. 2010;161(1):1-9.

35. Crisan-Dabija R, Grigorescu C, Pavel C-A. Tuberculosis and COVID-19: Lessons from the Past Viral Outbreaks and Possible Future Outcomes. Canada Respir J. 2020;2020:1401053.

36. Dheda K, Gumbo T, Gandhi NR. Global control of tuberculosis: from extensively drug-resistant to untreatable tuberculosis. Lancet Respir Med. 2014;2 (4):321-38.

37. Yasri S, Wiwanitkit V. Tuberculosis and novel Wuhan coronavirus infection: Pathological interrelationship. Indian J Tuberc. 2020;67(2):264.

38. Tamuzi JL, Ayele BT, Shumba CS. Implications of COVID-19 in high burden countries for HIV/TB: A systematic review of evidence. BMC Infect Dis. 2020;20(1):744.

39. Gao Y, Liu M, Chen Y, Shi S, Geng J, Tian J. Association between tuberculosis and COVID-19 severity and mortality: A rapid systematic review and meta-analysis. J Med Virol. 2020.

40. Motta I, Centis R, D'Ambrosio L. Tuberculosis, COVID-19 and migrants: Preliminary analysis of deaths occurring in 69 patients from two cohorts. Pulmonol. 2020;26(4):233-40.

41. Stochino C, Villa S, Zucchi P, Parravicini P, Gori A, Raviglione MC. Clinical characteristics of COVID19 and active tuberculosis co-infection in an Italian reference hospital. Eur Respir J. 2020;56(1): 2001708.

42. Qin C, Zhou L, Hu Z. Dysregulation of Immune Response in Patients With Coronavirus 2019 (COVID-19) in Wuhan, China. Clin Infect Dis. 2020;71(15):762-8.

43. Shi Y, Wang Y, Shao C, Huang J, Gan J, Huang X, Bucci E, Piacentini M, Ippolito G, Melino G. COVID-19 infection: the perspectives on immune responses. Cell Death Differ. 2020;27(5):1451-4.

44. Singh V, Sharma BB, Patel V. Pulmonary sequelae in a patient recovered from swine flu. Lung India. 2012;29(3):277-9.

45. Noymer A. The 1918-19 influenza pandemic affected tuberculosis in the United States: reconsidering
Bradshaw, Smith, and Blanchard. Biodemography Soc Biol. 2008 Fall;54(2):125-33; discussion 134-40.

46. Pawlowski A, Jansson M, Sköld M, Rottenberg ME, Källenius G. Tuberculosis and HIV co-infection. PLoS Pathog. 2012;8(2):e1002464.

47. Barnes PF, Bloch AB, Davidson PT, Snider DE. Tuberculosis in patients with human immunodeficiency virus infection. $\mathrm{N}$ Eng $\mathrm{J}$ Med. 1991;324(23):1644-50.

48. Alene KA, Wangdi K, Clements ACA. Impact of the COVID-19 Pandemic on Tuberculosis Control: An Overview. Trop Med Infect Dis. 2020;5(3):123.

49. Organization WH. WHO operational handbook on tuberculosis: module 1: prevention: tuberculosis preventive treatment. Available at: https://www.who.int/publications/i/item/9789240002 906. Accessed on 20 November 2020.

50. McQuaid CF, McCreesh N, Read JM, et al. The potential impact of COVID-19-related disruption on tuberculosis burden. Eur Respir J. 2020;56(2):2001718.

51. Sumner A, Hoy C, Ortiz-Juarez E. Estimates of the impact of COVID-19 on global poverty. Available T: https://www.wider.unu.edu/publication/estimatesimpact-covid-19-global-poverty. Accessed on 20 November 2020.

52. Tackling poverty in tuberculosis control. Lancet . 2005;366(9503):2063.

53. Spence DP, Hotchkiss J, Williams CS, Davies PD. Tuberculosis and poverty. BMJ. 1993;307(6907): 759-61.

54. Oxlade O, Murray M. Tuberculosis and poverty: why are the poor at greater risk in India?. PloS one. 2012; 7(11):e47533.

Cite this article as: Akhtar MM, Alotaibi ST, Althubeti AF, Alharthi SA, Alhassan SH, Bukhari MA. The potential impact of COVID-19 infection on tuberculosis: a literature review Int J Community Med Public Health 2021;8:937-42. 